\title{
论 文
}

\section{新疆哈密翼龙化石风化机理初步研究}

\author{
李颖 ${ }^{1,2 \dagger}$, 罗武千 ${ }^{1,2 \dagger}$, 杨益民 ${ }^{1,2}$, 蒋顺兴 ${ }^{1,3}$, 汪篠林 ${ }^{1,3,4^{*}}$
}

1. 中国科学院古脊椎动物与古人类研究所脊椎动物演化与人类起源重点实验室, 北京 100044 ;

2. 中国科学院大学考古学与人类学系, 北京 100049 ;

3. 中国科学院生物演化与环境卓越中心, 北京 100044;

4. 中国科学院大学地球与行星科学学院, 北京 100049

* 通讯作者, E-mail: wangxiaolin@ivpp.ac.cn

$\dagger$ 同等贡献

收稿日期: 2020-04-20; 收修改稿日期: 2020-10-21; 接受日期: 2020-11-10; 网络版发表日期: 2021-01-19

国家自然科学基金项目(批准号: 41572020, 41688103)、中国科学院青年创新促进会基金项目(编号: 2019075)和哈密市政府合作项目资助

摘要＼cjkstart哈密翼龙化石的发现对探讨翼龙习性、起源与演化具有重要意义. 但随着保存环境的变化, 化石骨骼产生 了明显的开裂剥落等风化现象，严重威胁化石保存。本文利用X射线荧光光谱法(XRF)等多种方法对骨骼化石进 行测试，以探讨其风化机理. 分析表明，翼龙中空骨骼内的填充物主要是方解石，夹杂少量石英和长石等碎屑颗 粒. 骨骼化石的主要成分是差基磷灰石，但部分羟磷灰石中的 $\mathrm{PO}_{4}{ }^{3-}$ 被 $\mathrm{CO}_{3}{ }^{2-}$ 所替代. 在骨骼脉管道内填充着少量 方解石和锰质胶结物, 化石的磷酸盐结晶度指数高达 4.17 , 可见翼龙骨骼经历了明显的成岩作用. 骨骼化石中含 有大量 $\mathrm{Cl}^{-} 、 \mathrm{NO}_{3}{ }^{-} 、 \mathrm{SO}_{4}{ }^{2-} 、 \mathrm{Na}^{+}$和 $\mathrm{Ca}^{2+}$ 等离子, 总可溶盐含量高达 $35584.41 \mu \mathrm{g} \mathrm{g}^{-1}$. 根据以上分析结果, 本文将翼龙 化石风化的原因概括如下: 一方面, 在戈壁温差剧烈变化下, 化石围岩、骨骼化石和内部填充物等各部分中所含 物质的热膨胀系数不同, 造成热应力局部集中导致化石开裂剥落; 另一方面, 在温湿度变化时, 骨骼当中所含大量 可溶盐产生的结晶压、水化压等压力超过了骨骼化石的抗拉强度，对化石造成破坏. 因此，建议先对此类化石进 行盐害治理及加固处理, 然后将其存放于温湿度较为恒定的环境中.

关键词哈密翼龙, 化石风化, 差基磷灰石, 热膨胀系数, 新疆

\section{1 引言}

古生物化石是珍贵的不可再生自然遗迹. 人们通 过研究化石，对丰富多彩的史前生命世界有了更深入 的了解. 从全世界为数不多的翼龙化石产地来看，新 疆哈密地区是非常独特的。它不仅是世界上迄今为止 分布面积最大和最富集的翼龙化石产地，也是唯一一
处同时三维立体保存翼龙蛋、翼龙胚胎和幼年到成年 雌雄翼龙个体的化石遗址(汪篠林等, 2018). 通过对哈 密翼龙化石的研究, 学者们对翼龙的雌雄性双型、个 体发育、生殖与胚胎发育、生存环境与集群死亡、生 态习性等都有了进一步的认识(Martill, 2014; Wang等, 2014, 2017; Deeming, 2017). 由于化石产自极干旱、高 盐碱地区，将其运至北京之后，随着保存环境的变化，

\footnotetext{
中文引用格式: 李颖, 罗武干, 杨益民, 蒋顺兴, 汪筕林. 2021. 新疆哈密翼龙化石风化机理初步研究. 中国科学: 地球科学, 51(3): 398-410, doi: 10.1360/SSTe2020-0103

英文引用格式: Li Y, Luo W, Yang Y, Jiang S, Wang X. 2021. A preliminary study of the weathering mechanism of fossilized cretaceous Hamipterus bones. Science China Earth Sciences, 64(3): 458-469, https://doi.org/10.1007/s11430-020-9702-8
} 
化石产生了诸多自然风化现象，如化石围岩的粉化以 及骨骼的开裂和剥落破碎, 这严重影响到化石保存、 陈列展出及相关科研工作的进行.

大多数骨骼化石经过化石风化作用后, 其抗风化 能力提高, 但仍有部分化石会出现开裂剥落等风化现 象. 已有学者针对风化的化石展开了相关保护研究工 作. 例如, 有学者利用傅里叶变换红外光谱(FTIR)、X 射线衍射(XRD)等技术分析了我国自贡、诸城等地恐 龙化石骨骼和围岩的保存状况(邓建国等, 2010b), 并 使用新型纳米二氧化硅防护材料对化石进行了加固保 护(邓建国等, 2010a). 也有学者使用计算机断层成像 (CT)扫描等技术对西班牙Atapuerca遗址出土的更新 世人类下领骨进行深入了解之后, 使用 $2 \mathrm{~A}$ (酒精: 水 $=1: 1$ )溶液及B72等试剂对化石进行清理、黏接(LópezPolín等, 2008). 研究还发现, 胶原蛋白等有机物分解使 骨骼弹性和㓞性下降以及黄铁矿、针铁矿等矿物的沉 积是象化石风化的重要原因, 并指出使用纳米羟基磷 灰石等材料对化石进行加固保护效果较好, 同时提到 为确保化石的安全稳定, 应将其存放于严格控制的环 境中(Turner-Walker, 1998; Wang等, 2007; 刘林西, 2014). 为了延长化石寿命, 常使用一些化学试剂对其 进行加固保护, 但这些人为干预是否会影响人们对化 石的后续研究也是学界非常关注的问题. 比如, 有研 究对清理加固后的化石进行扫描电子显微镜(SEM)、

$\mathrm{XRD}$ 等分析手段，从而评估保护后的化石是否影响后 续表面形貌分析工作以及化学试剂的引入对后续 DNA和稳定同位素测试是否产生影响(Howie，1984; López-Polín, 2012; Mallouchou等, 2019).

可见, 已有研究主要集中于化石的清理加固等保 护工作上, 对于化石本体的风化原因关注较少. 仅有 少量关于恐龙化石和更新世哺乳动物化石的风化机理 研究(Turner-Walker, 1998; 张尚坤等, 2019)以及对化石 围岩的风化机理分析和加固保护实验(李颖等, 2019; Peng等, 2020). 对翼龙这一类骨壁薄、骨骼中空的化 石保护研究基本属于空白. 加之哈密翼龙化石产地位 于中国西北新疆地区, 其强烈干旱和高盐碱环境也是 威胁众多文物稳定的原因之一(梁涛, 2009), 化石风化 现象与其长期埋藏在高盐碱地区是否有关也需要研 究. 明确翼龙化石风化机理可以为后续保护方案的制 定提供详实依据, 具有重要意义. 因此, 本文利用X射 线苂光光谱(XRF)、XRD、FTIR等现代分析手段对哈
密翼龙化石进行检测, 分析导致化石风化的原因, 为保 护工作奠定基础.

\section{2 分析材料、实验方法及结果}

\section{1 材料描述}

本次实验的材料均采自天山哈密翼龙(Hamipterus tianshanensis)化石原产地一一新疆哈密戈壁. 化石主 要集中埋藏于湖泊风暴岩中, 其岩性主要以中细粒砂 岩为主, 化石与红褐色泥质砾屑共存, 化石保存无定 向性、骨骼大多分离、数量巨大(Wang等, 2014). 翼 龙化石的特殊之处就在于其骨壁薄、骨骼中空, 且中 空骨骼内部有砂岩填充, 其颜色有浅色(图1a)和深色 (图1b)之分, 偶见化石内结晶良好的无色透明晶体(图 1f). 同时, 可见化石骨骼出现开裂剥落等风化现象(图 1c、1e).

\section{2 实验方法与结果}

\subsubsection{XRF}

为明确骨骼化石部分的元素组成, 使用能量色散 型X射线苂光光谱仪(Horiba公司的XGT-7000型, 日 本)对化石样品进行测定, $\mathrm{X}$ 光管电压 $30 \mathrm{kV}$, 电流 $0.15 \mathrm{~mA}$; 信号采集时间 $100 \mathrm{~s}$, 光斑大小为 $1.2 \mathrm{~mm}$. XRF 结果见表1.

从XRF数据来看, 翼龙骨骼部分只含有极少量的 硅、铝, 主要是钻和磷, 符合羟基磷灰石的元素特征. 其钻磷比 $(\mathrm{Ca} / \mathrm{P}$ 约为 1.16$)$ 明显低于羟基磷灰石 $(\mathrm{Ca} / \mathrm{P}$ 约 为1.67), 表明在长期地下埋藏过程中, 土壤中的其他 阳离子很可能已替代了部分羟基磷灰石中的钲离子 (Newesely，1989). 值得注意的是, 骨骼部分有一定的 钠、硫元素, 推测有可能是钠盐.

翼龙化石填充物的硅、铝含量较高, 同时也含有 较高的钙. 除此之外, 还含有少量的钠、镁和铁. 深色 与浅色填充物相比, 钙明显下降, 锰上升, 其他元素差 异不太明显. 由此表明, 深色和浅色填充物的成分大致 相同, 主要差别是深色填充物锰含量高.

\subsubsection{XRD}

YL-W、YL-B和YL-G三件样品的XRD实验委托 西安地质矿产研究所完成. 仪器型号为 $\mathrm{D} / \mathrm{max}-2500 \mathrm{X}$ 射线衍射仪, 实验条件为电压 $40 \mathrm{kV}$, 电流 $200 \mathrm{~mA}, \mathrm{Cu}$ 靶, 

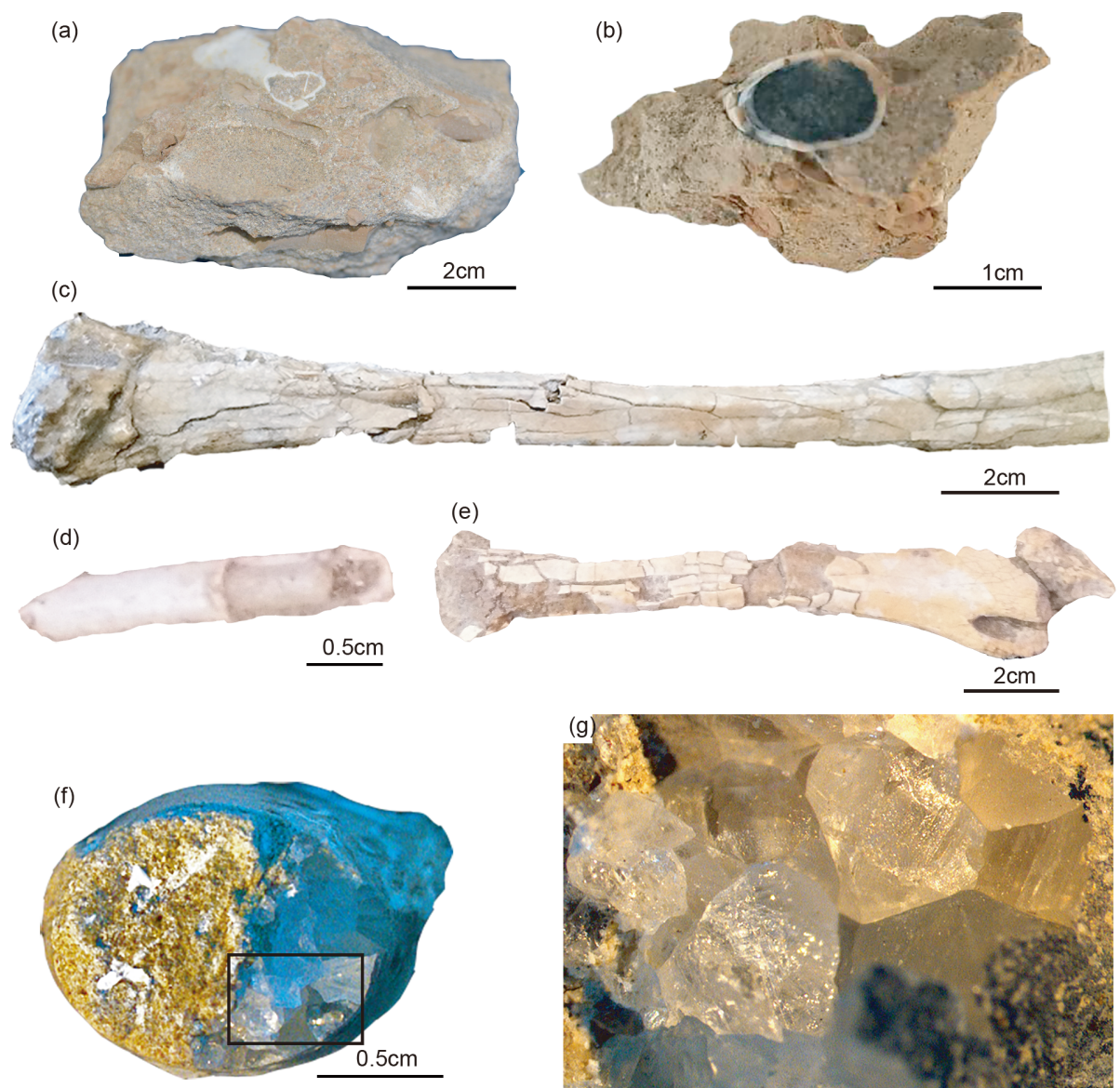

(e)

图 1 哈密翼龙骨骼化石样品

(a) 围岩包裹着骨骼化石, 中空骨骼内部为浅色填充物; (b) 围岩包裹着骨骼化石, 中空骨骼内部为深色填充物; (c) 开裂的骨骼化石; (d) 骨骼化 石及其内部填充的白色半透明晶体; (e) 表面剥落的骨骼化石; (f) 中空骨骼化石的填充物横截面, 可见部分结晶良好的无色透明晶体; (g) 图1f 黑框区域的放大图, 可见粒度粗、自形程度好的无色透明晶体

表 1 骨骼化石及内部填充物的XRF结果 $(w t \%)^{a)}$

\begin{tabular}{cccccccccccccc}
\hline 编号 & $\mathrm{Na}_{2} \mathrm{O}$ & $\mathrm{MgO}$ & $\mathrm{Al}_{2} \mathrm{O}_{3}$ & $\mathrm{SiO}_{2}$ & $\mathrm{P}_{2} \mathrm{O}_{5}$ & $\mathrm{SO}_{3}$ & $\mathrm{Cl}$ & $\mathrm{K}_{2} \mathrm{O}$ & $\mathrm{CaO}$ & $\mathrm{TiO}_{2}$ & $\mathrm{MnO}^{2}$ & $\mathrm{Fe}_{2} \mathrm{O}_{3}$ & $\mathrm{SrO}^{2}$ \\
\hline $\mathrm{YL}-\mathrm{B}$ & 3.24 & 6.26 & 11.71 & 40 & 0.13 & 0.44 & - & 0.63 & 22.44 & - & 12.83 & 2.06 & 0.07 \\
$\mathrm{YL}-\mathrm{W}$ & 2.67 & 2.81 & 7.86 & 36.44 & 0 & 2.33 & - & 1.72 & 41.64 & 0.4 & 0.08 & 4.01 & 0.03 \\
$\mathrm{YL}-\mathrm{G}$ & 2.71 & 1.14 & 1.18 & 4.61 & 39.92 & 1.6 & 0.03 & 0.02 & 46.16 & - & - & - & - \\
\hline
\end{tabular}

a) YL-B为骨骼内部深色填充物, YL-W为骨骼内部浅色填充物, YL-G为骨骼化石, 下同

石墨单色器滤波. 测试前将样品研磨成细小粉末, 在样 品槽内压成平面测试. 定量方法使用基本强度对比法

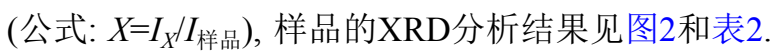

另外, 针对骨骼内部填充的良好结晶样品, 用手术 刀取一定晶体颗粒于研针中研磨成细小粉末后，利用 MiniFlex II 型X射线衍射仪(日本理学公司)对样品进 行分析, 实验条件如下: 工作电压 $30 \mathrm{kV}$, 电流 $15 \mathrm{~mA}, \mathrm{Cu}$
靶. 发散狭缝、防散射狭缝和接收狭缝依次为 $1.25^{\circ}$ 、 $1.25^{\circ}$ 和 $0.3 \mathrm{~mm}$. 扫描范围为 $10^{\circ} \sim 75^{\circ}$, 扫描速度为 $3^{\circ} \%$ $\min$, 结果如图3所示. 根据衍射图谱可知, 骨骼化石内 填充的白色半透明物质为方解石.

\subsubsection{FTIR}

用手术刀刮取少许骨骼化石于玛瑙研钵中，以待 

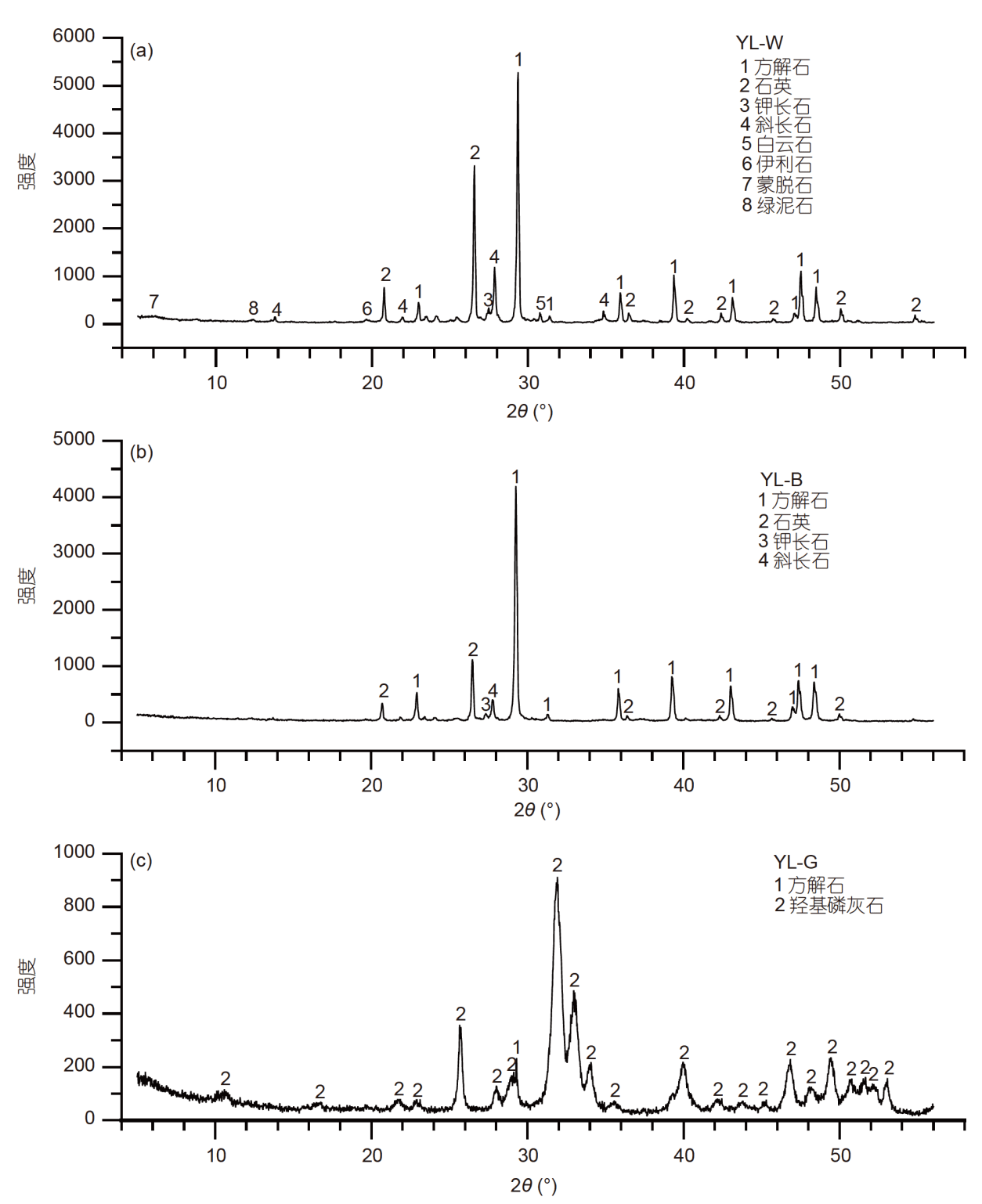

图 2 XRD光谱图

(a) 中空骨骼化石内部浅色填充物; (b) 中空骨骼化石内部深色填充物; (c) 翼龙骨骼化石

测样品与溴化钾 $1: 100$ 的比例混合. 研磨均匀后放入压 片磨具内压制成透明或者半透明的锭片, 利用NICOLET 6700型傅里叶变换红外光谱仪(Thermo Scientific, 美国)进行测试, 所选红外光谱范围为 $4000 \sim 400 \mathrm{~cm}^{-1}$, 光谱分辨率为 $4 \mathrm{~cm}^{-1}$, 扫描信号累加 32 次, 用Omnic 8.0 软件进行数据处理.

分析结果如图4所示, $3420 \mathrm{~cm}^{-1}$ 处宽吸收峰为羟基 的伸缩振动, $1637 \mathrm{~cm}^{-1}$ 为羟基的弯曲振动, 说明骨骼化 石中存在着基或者吸附水; 1456 和 $1425 \mathrm{~cm}^{-1}$ 处为 $\mathrm{CO}_{3}{ }^{2-}$
基团的反对称伸缩振动吸收峰; $873 \mathrm{~cm}^{-1}$ 为 $\mathrm{CO}_{3}{ }^{2-}$ 基团 的面外弯曲振动; $1041 \mathrm{~cm}^{-1}$ 处极强尖锐吸收峰为 $\mathrm{PO}_{4}{ }^{2-}$ 基团的反对称伸缩振动, $965 \mathrm{~cm}^{-1}$ 为 $\mathrm{PO}_{4}{ }^{2-}$ 基团的对称 伸缩振动, 605 和 $570 \mathrm{~cm}^{-1}$ 为 $\mathrm{PO}_{4}{ }^{2-}$ 基团的不对称变角振 动, $469 \mathrm{~cm}^{-1}$ 为 $\mathrm{PO}_{4}{ }^{2-}$ 基团的对称变角振动(翁诗甫和徐 怡庄, 2016).

研究表明, 羟基磷灰石中的碳酸根存在A、B两种 替换方式. 其中 $\mathrm{A}$ 型为 $\mathrm{CO}_{3}{ }^{2-}$ 替代 $\mathrm{OH}^{-}$, 其红外光谱上 $\mathrm{CO}_{3}{ }^{2-}$ 所处的位置为 $880 、 1450 、 1545 \mathrm{~cm}^{-1} ; \mathrm{B}$ 型为 


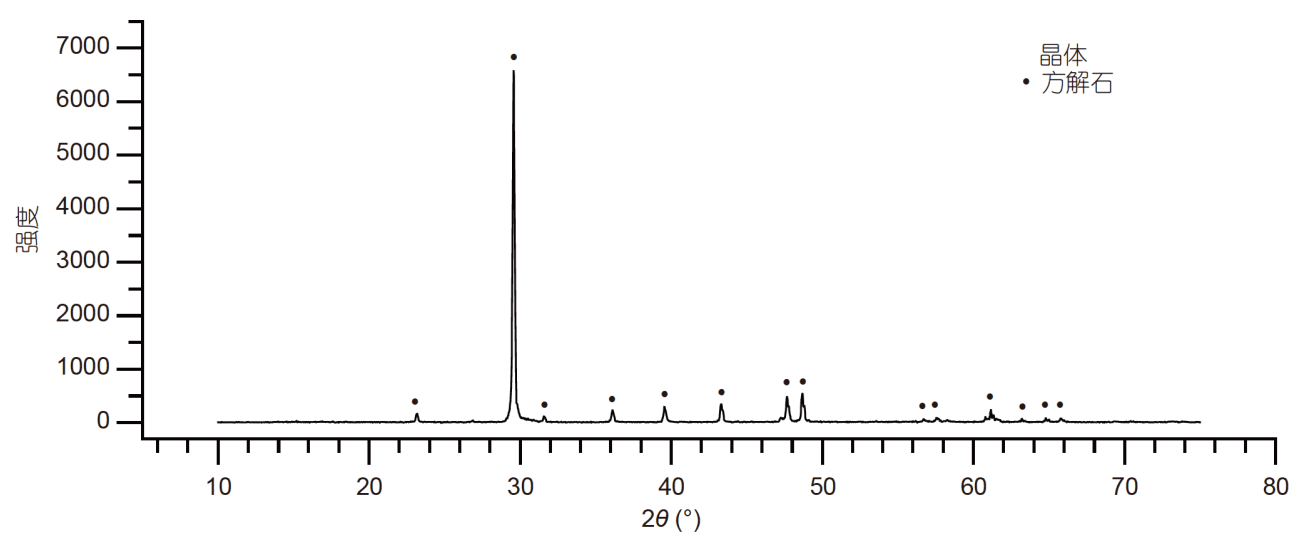

图 3 白色半透明晶体XRD图谱

表 $2 X$ 射线衍射定量分析测试数据 $(w t \%)^{a)}$

\begin{tabular}{cccc}
\hline 样品编号 & YL-W & YL-B & YL-G \\
\hline 石英 & 26.8 & 15.4 & - \\
斜长石 & 12.7 & 11.1 & - \\
钾长石 & 4.1 & 3.8 & - \\
方解石 & 45.1 & 69.7 & 2 \\
白云石 & 2.3 & - & - \\
绿泥石 & 2.0 & - & - \\
伊利石 & 3.0 & - & - \\
蒙脱石 & 4.0 & - & - \\
羟基磷灰石 & - & - & 98 \\
\hline
\end{tabular}

a) 从XRD结果可以看到, 化石骨骼样品主要为羟基磷灰石, 含 有极少量方解石. 填充物主要成分是方解石, 还有一定量的长石和 石英. 浅色填充物除上述矿物外, 还含有一定量的白云石和黏土矿 物

$\mathrm{CO}_{3}{ }^{2-}$ 替代 $\mathrm{PO}_{4}{ }^{3-}$, 其红外光谱上 $\mathrm{CO}_{3}{ }^{2-}$ 所处的位置为 875、1410、1455 $\mathrm{cm}^{-1}$ (Fleet和Liu, 2003). 由图4可知, 样品在1456、1425和 $873 \mathrm{~cm}^{-1}$ 处存在三个吸收峰, 表明 化石中存在 $\mathrm{CO}_{3}{ }^{2-}$ 替代 $\mathrm{PO}_{4}{ }^{3-}$ 的现象( $\mathrm{B}$ 型替换), 说明翼 龙骨骼在长期地下埋藏过程中, 周围环境中的 $\mathrm{CO}_{3}{ }^{2-}$ 替 换了羟磷灰石中的部分 $\mathrm{PO}_{4}{ }^{3-}$.

骨骼化石的磷酸盐结晶度指数PCI (phosphate crystallinity index)可以进一步反映其所经历的成岩作 用程度, $\mathrm{PCI}$ 的值越大, 即 $v 4 \mathrm{PO}_{4}{ }^{3-}$ 的分裂程度越大, 表 明样品的结晶程度越高(赖琛, 2006). 一般来说, 现代 骨骼的PCI值较低(2.8 3.0), 而经历成岩作用后, 其PCI 值会增高(Berna等, 2004). 参照已有文献提供的计算公 式可以得出骨骼化石的PCI值为4.17 (Shemesh, 1990; Weiner和Bar-Yosef, 1990), 表明其在地下埋藏过程中

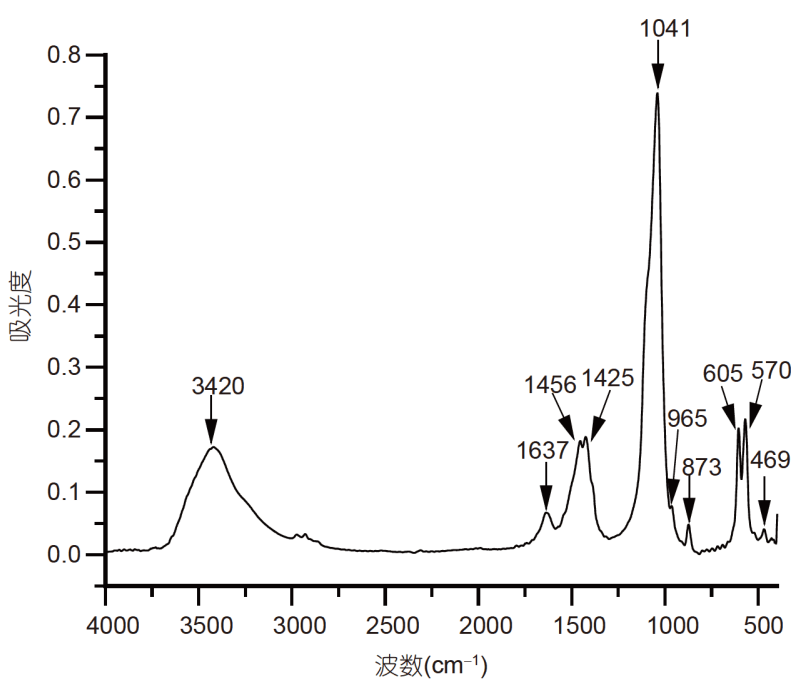

图 4 骨骼化石红外图谱

受到了明显的成岩作用.

\subsection{4 骨组织学切片及其显微观察}

选取剥落下来的翼龙骨骼化石碎片, 将其嵌入 EXAKT Technovit单组分树脂中, 置于EXAKT 300CP 自动切片机沿骨骼纵轴切割, 抛光至约 $50 \mu \mathrm{m}$ 后, 使用 EXAKT 400CP自动磨片机用P500和P4000砂纸打磨至 约 $30 \mu \mathrm{m}$. 将制作好的骨组织切片置于蔡司公司生产的 Axio Imager A2m型显微镜下进行观察, 结果见图5.

在单偏光下可见部分脉管道(可能为血管和淋巴 等的腔隙)交汇联结成网状(图5a), 表面有黑色斑迹, 推 测这是细菌侵蚀所致(Hackett，1981; Turner-Walker, 2012)，脉管内偶见晶体填充(图5b), 在正交偏光下显 示高级白(图5d), 疑似方解石. 骨内层可见生长停滞 
(a)

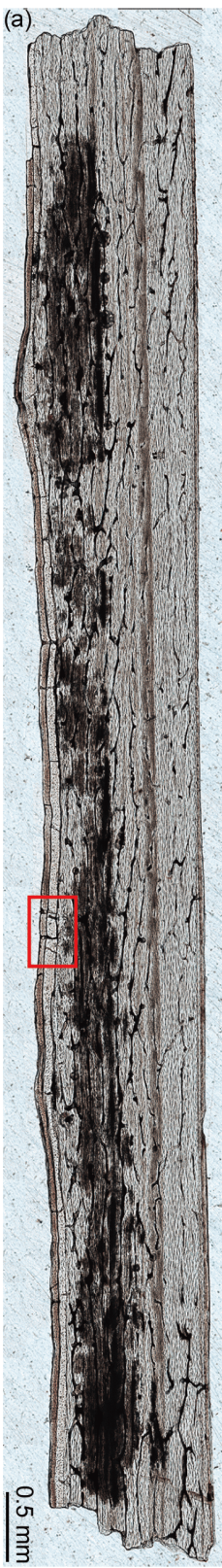

(b)
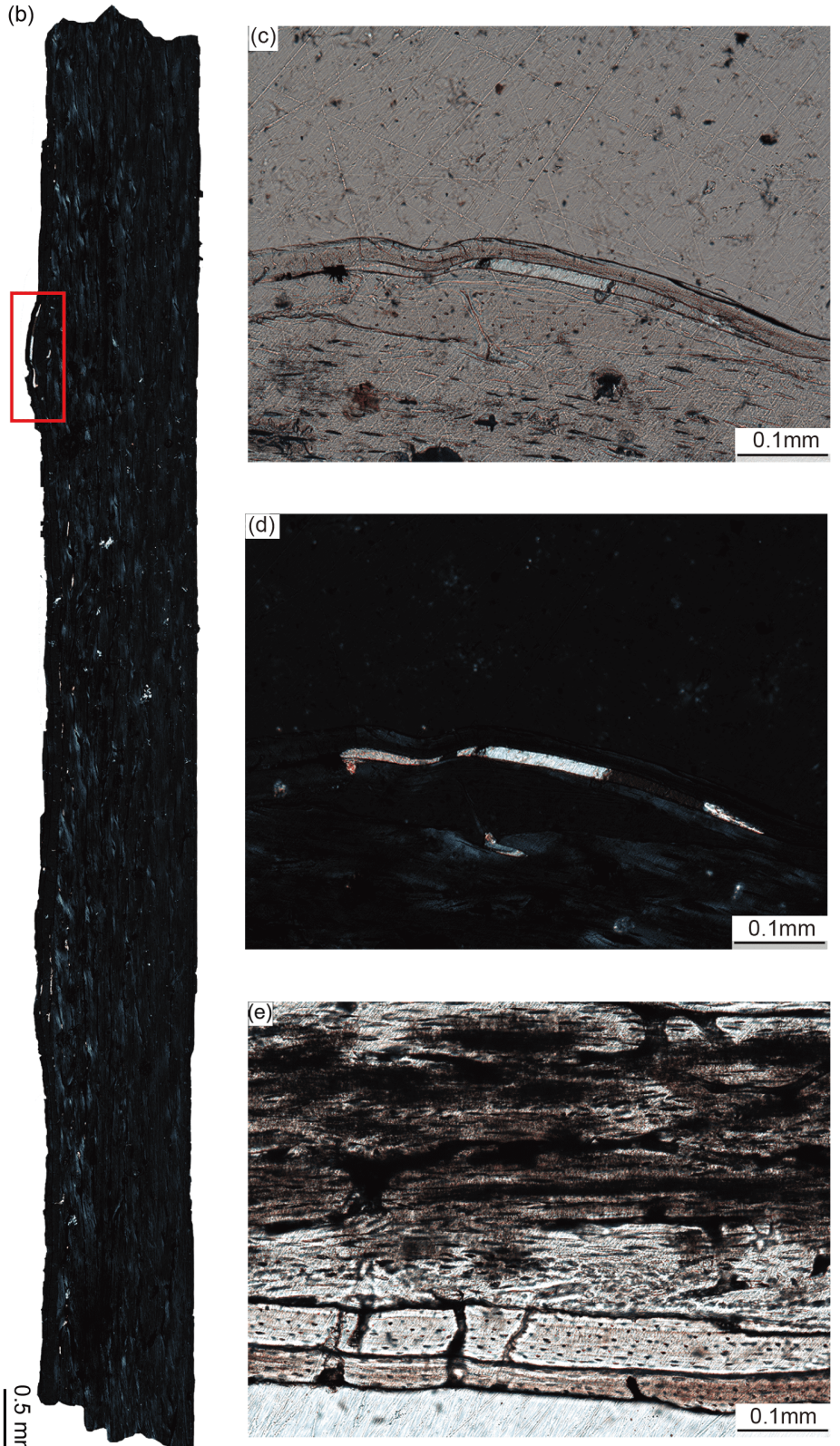

图 5 骨组织学切片(纵切)镜下观察

(a) 单偏光, 可见交汇成网状的脉管道, 表面有黑色斑迹; (b) 正交偏光, 大量脉管道内填充具高级白干涉色晶体; (c) 图5b红色区域的单偏光; (d) 图5b红色区域的正交偏光, 可见空隙内填充的具高级白干涉色晶体; (e) 图5a红色区域单偏光, 骨内层见生长停滞线, 有细小裂纹, 在黑色斑 迹的遮盖下依稀可见脉管道

线, 且能观察到细小裂缝(图5e).

\subsection{5 扫描电子显微镜形貌观察及能谱分析}

将样品表面的浮尘用洗耳球吹去，使用导电胶将 样品固定在样品台上，喷金后进行SEM分析．形貌观
察采用德国Carl Zeiss公司生产的EVO 25型扫描电子 显微镜, 实验电压为 $8 \sim 16 \mathrm{kV}$, 结果如图6所示.

通过扫描电子显微镜观察可知, 骨骼化石与其内 部填充物之间存在一定的裂隙，两者并没有紧密结合 (图6a)，已经开裂的骨骼化石在外力扰动下非常容易 

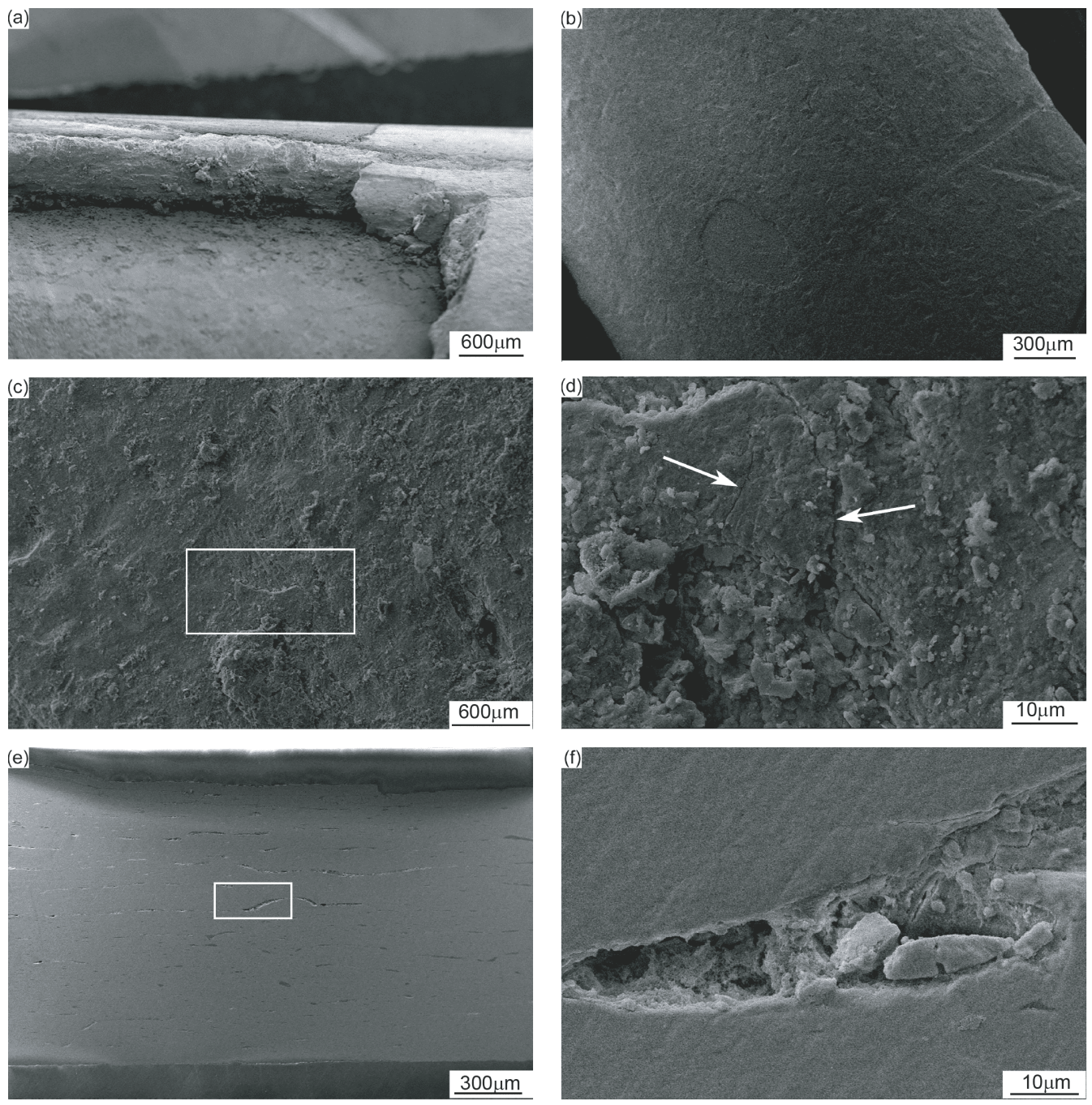

图 6 骨骼化石及其骨组织切片扫描电子显微镜照片

(a) 骨壁断面观察照片; (b) 低倍数下骨骼化石外表面; (c) 高倍数下骨骼外表面, 表面凹凸不平, 隐约可见微小裂隙; (d) 图6c中白色方框放大图 像, 微裂隙清晰可见(箭头所指处); (e) 骨组织切片(纵轴切割)的二次扫描电子显微镜电镜照片, 可见凹陷的脉管道; (f) 图6e中白色方框放大图 像, 凹陷的脉管道内有晶体填充

剥落. 骨骼化石表面看似平整(图6b), 不存在明显裂隙, 但在高倍数下，依旧可以观察到细小裂隙(图6c、6d), 这些微裂隙在外力作用下会不断扩大，进而形成肉眼 可见的裂隙. 高倍下观察骨组织学切片发现, 在骨骼 的脉管道内有很多结晶颗粒(图6e、6f).

成分分析使用荷兰Phenom World公司的Phenom $\mathrm{XL}$ 型扫描电子显微镜, 扫描电压为 $15 \mathrm{kV}$. 在背散射模 式下, 随机选取脉管道内亮白色结晶区域和暗灰色结 晶区域进行面扫描，同时，着重选取在偏光显微镜下 观测到高级白的区域(图5d)进行能谱面扫描分析，以
确定其成分是否为方解石.

在背散射模式下，信号强度随着样品表层平均原 子序数增大而加强, 反映在背散射图像上就是原子序 数越大的区域就会越亮. 从图7a中可以观察到, 脉管 道中填充的晶体, 有部分呈现非常亮的区域, 也有部 分与周围没有明显明暗差别的区域, 可知在脉管道内 填充了不同的物质. 能谱分析结果表明, 亮色区域的 锰、氧和氟含量非常高, 而几乎没有钻和磷, 推测这 些亮色区域填充的是锰质胶结物. 而与周围没有明显 色差变化的区域, 其钲和氧高, 基本不见磷和氟, 表明 


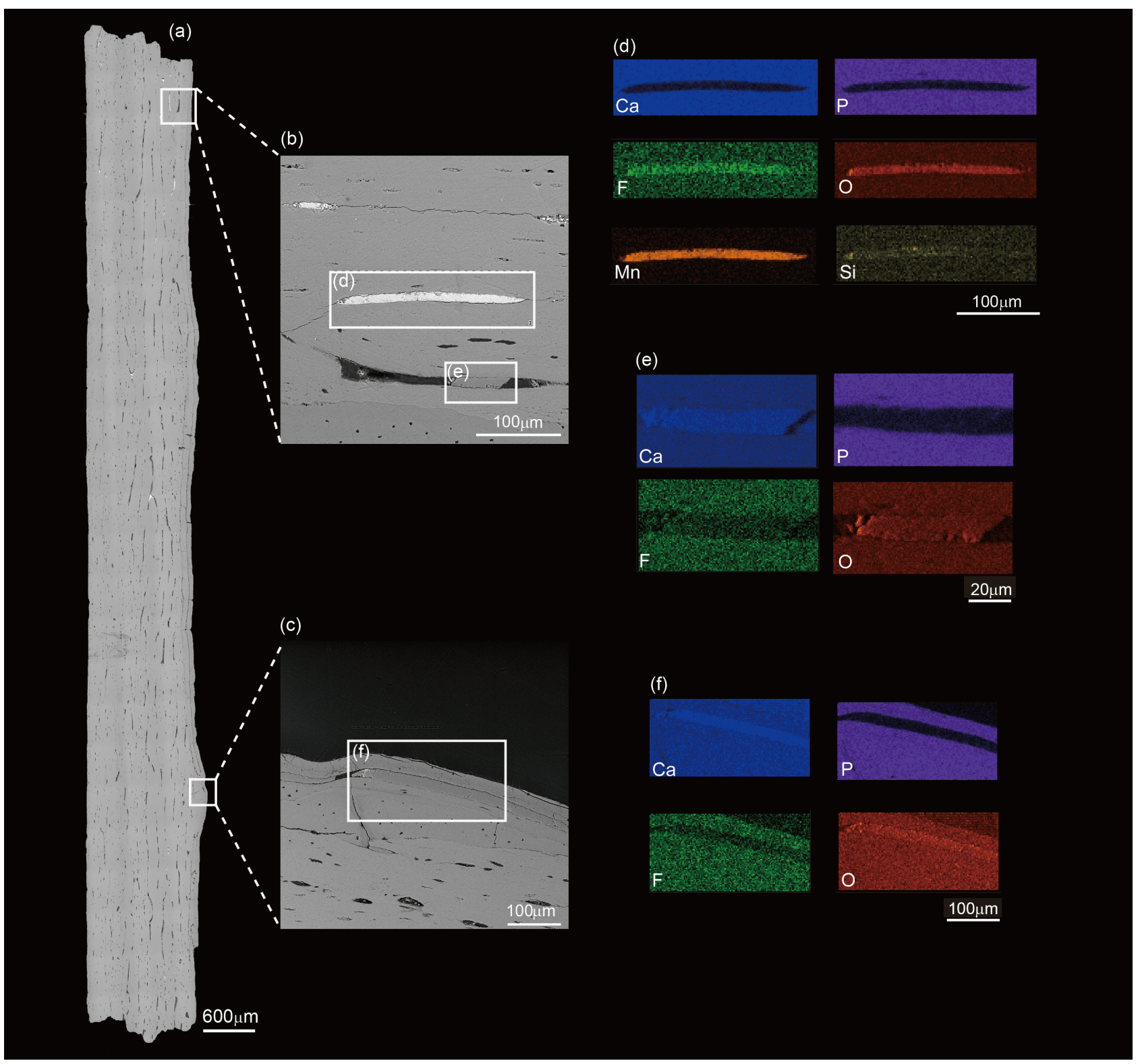

图 7 SEM-EDS面扫描结果

(a) 骨组织学切片背散射模式下电镜照片; (b) 图7a上部方框放大图, 见脉管道内填充晶体有明暗之分; (c) 图7a下部方框放大图, 观察区域与光 学显微镜下观察图 5c、5d相同; (d) 图7b亮色区域能谱扫描分析, 脉管道内锰氟氧含量高, 而基本没有钙磷; (e) 图7b暗色区域能谱扫描分析, 脉 管道内钲氧含量高, 基本不含磷, 氟含量下降; (f) 图7c白框区域能谱扫描分析, 在偏光显微镜下显示高级白的区域钲氧含量高, 基本不含磷, 氟 含量下降

这些矿物是方解石．在正交偏光下显高级白干涉色的 区域，其钻氧含量高，而基本不见磷氟元素，说明也是 方解石.

在骨骼切片中观察到脉管道内填充的方解石和锰 质胶结物，应是有机物在长期埋藏过程中腐烂消失后， 地下水中的矿物成分填充于骨骼空腔处的结果(杜远
生和童金南, 2009). 在翼龙埋藏初期, 有机质腐烂过程 中会产生大量的 $\mathrm{H}_{2} \mathrm{~S}$ 和 $\mathrm{CO}_{2}$ 等酸性气体，这些气体溶解 在水中, 使化石微环境的 $\mathrm{pH}$ 值降低, 此时并不利于碳 酸钙的沉积(Ronald, 1999). 当肉体腐烂殆尽, 微环境的 $\mathrm{pH}$ 值逐渐升高, 此时周围含碳酸钙的水体渗入骨骼, 并在空隙内开始沉淀结晶. 


\subsection{6 离子色谱}

为明确化石中可溶盐的种类及其含量, 使用日本 岛津公司生产的HIC-10A super IC型离子色谱分析仪 对样品进行检测. 样品处理过程参考李颖等(2019)的 实验方法. 离子色谱测试条件见表 3 , 测试结果见表4.

表4指出, $\mathrm{Na}^{+} 、 \mathrm{Cl}^{-}$和 $\mathrm{NO}_{3}{ }^{-}$在化石围岩和骨骼化 石当中的含量非常高, 而在骨骼内部填充物的含量却 比较低. 产生这种现象的原因是, 当环境湿度升高时, $\mathrm{NaCl}$ 等可溶盐发生溶解并以离子形式从浓度高的化 石围岩运移扩散到化石骨骼当中. 但是, 由于羟基磷灰 石对 $\mathrm{Cl}^{-} 、 \mathrm{Na}^{+}$等离子均有一定的吸附能力(沈卫等, 1996), 可溶盐离子运移到骨骼化石中后会被羟基磷灰 石吸附，使得骨骼化石中含盐量明显高于中空骨骼内 填充物的含盐量. 骨骼化石当中的硫酸根离子明显高 于其他部位，有可能是在翼龙埋藏之后有机物腐烂分 解，在有氧环境下，有机物中的硫氧化成硫酸根的结 果(Weiner, 2010). 骨骼化石中高硫酸根含量的具体原 因还有待后续进一步研究.

\section{3 讨论}

基于以上分析，可对骨骼化石及其填充物成分有

表 3 离子色谱测试条件

\begin{tabular}{ccc}
\hline 项目 & 阴离子参数 & 阳离子参数 \\
\hline 流动相 & $0.70 \mathrm{mmol} \mathrm{L}^{-1}$ 的 & $0.35 \mathrm{mmol} \mathrm{L}^{-1}$ 的 \\
柱温 & $\mathrm{H}_{2} \mathrm{SO}_{4}$ 水溶液 & $\mathrm{Na}_{2} \mathrm{CO}_{3}$ 水溶液 \\
流速 & $40^{\circ} \mathrm{C}$ & $45^{\circ} \mathrm{C}$ \\
柱压 & $1.0 \mathrm{~mL} \mathrm{~min}{ }^{-1}$ & $0.8 \mathrm{~mL} \mathrm{~min}{ }^{-1}$ \\
进样量 & $3.7 \mathrm{MPa}$ & $11 \mathrm{MPa}$ \\
数据记录起止时 & $60 \mu \mathrm{L}$ & $60 \mu \mathrm{L}$ \\
\hline
\end{tabular}

较为清晰的认识. 骨骼化石以羟基磷灰石为主，含一 定量的碳羟磷灰石. 化石的磷酸盐结晶度 $(\mathrm{PCI}=4.17)$ 远高于天然骨羟磷灰石(PCI在2.8 3.0), 表明化石经历 了严重的成岩作用(Berna等, 2004). 化石脉管道内填充 方解石及锰质胶结物等次生矿物, 次生方解石填充在 骨骼有机物分解后的微空隙中是较为普遍的现象 (Monge等, 2014). 这是由于骨骼脉管道内的有机质在 翼龙死后分解形成空腔, 之后经在富碳酸钻质的溶液 环境中交代填充, 在空腔内结晶成方解石. 次生方解 石填充现象说明化石经历了干湿交替的环境变化 (Monge等, 2014). 锰填充在骨骼微孔隙中也是较为常 见的现象, 这是由于翼龙埋藏在含 $\mathrm{Mn}^{2+}$ 的地下水环境 下， $\mathrm{Mn}^{2+}$ 随着水液进入骨骼毛细血管，或通过裂隙进 入骨骼空腔，当溶液蒸发后导致锰在骨骼中富集 (Pfretzschner和Tütken, 2011). 一般认为, 锰氧化物的 存在表明化石沉积在氧化环境(Monge等, 2014). 然而, 由于 $X$ 射线衍射分析的限制，当检测物成分低于 $5 \%$ 时， 其衍射峰不明显(Ressler等, 2001), 导致现有数据无法 明确锰的具体矿物组成. 因此, 化石中锰沉淀富集的具 体原因有待进一步研究, 如微生物是否参与锰的沉淀 和氧化进程等还有待确认. 翼龙中空骨骼内填充物的 主要成分是方解石, 含一定量石英长石等碎屑颗粒. 此外, 浅色填充物中还含有少量白云石和黏土矿物, 而深色填充物的锰含量较高. 基于以上对骨骼化石的 分析, 初步推断骨骼化石开裂剥落破碎的原因主要 如下.

首先是物理风化. 主要是指随着外界温度不断变 化, 化石各组分之间热膨胀系数不同, 在化石内部产 生巨大应力导致化石开裂. 化石原埋藏在戈壁滩中, 参考塔克拉玛干沙漠的地表温度数据: 夏季地表温度

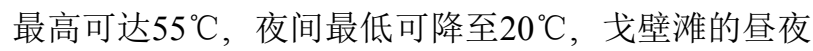
温差可达 $35^{\circ} \mathrm{C}$; 冬季地表最高温度 $5^{\circ} \mathrm{C}$, 最低温度零下

表 4 化石离子色谱数据 $\left(\mu \mathrm{g} \mathrm{g}^{-1}\right)^{\mathrm{a})}$

\begin{tabular}{ccccccccc}
\hline 样品编号 & $\mathrm{Na}^{+}$ & $\mathrm{K}^{+}$ & $\mathrm{Ca}^{2+}$ & $\mathrm{Mg}^{2+}$ & $\mathrm{Cl}^{-}$ & $\mathrm{NO}_{3}^{-}$ & $\mathrm{SO}_{4}^{2-}$ & 总计 \\
\hline F-Black & 315.60 & 95.03 & 2688.89 & 0.00 & 197.12 & 378.45 & 2391.71 & 6066.80 \\
F-White & 152.46 & 129.01 & 1589.02 & 0.00 & 54.66 & 67.42 & 362.56 & 2355.13 \\
F-Bone & 3679.23 & 69.47 & 7837.83 & 0.00 & 10866.17 & 4185.44 & 8946.27 & 35584.41 \\
F-Rocks & 5478.11 & 150.60 & 4159.94 & 255.46 & 14958.99 & 4173.35 & 199.48 & 29375.93 \\
F-Clay & 7971.75 & 354.61 & 10621.40 & 1151.23 & 29263.74 & 14178.72 & 174.15 & 63715.59 \\
\hline
\end{tabular}

a) F-Black为深色填充物; F-White为浅色填充物; F-Bone为骨骼化石; F-Rocks为化石围岩; F-Clay为化石围岩中的褐色泥砾 
$20^{\circ} \mathrm{C}$, 昼夜温差可达 $25^{\circ} \mathrm{C}$ (张文斌, 2016). 在巨大的温 差作用下, 由于化石各组分之间热膨胀系数不同, 在化 石内部产生巨大热应力. 具体来说, 应力的来源有两方 面. 一是在骨骼的脉管道等孔隙中存在一定量方解石. 方解石的热膨胀系数存在各向异性，即 $z$ 方向(晶体光 轴方向 $)$ 的热膨胀系数最大 $\left(\alpha_{\max }=26.5 \times 10^{-6} \mathrm{~K}^{-1}\right)$, 是热 胀冷缩性质; 而平行于 $x 、 y$ 平面任意方向的热膨胀系 数最小 $\left(\alpha_{\min }=-5.6 \times 10^{-6} \mathrm{~K}^{-1}\right)$, 是热缩冷胀性质 (吴福全 等，2016). 骨骼化石主要是羟基磷灰石，其热膨胀系 数为 $13.9 \times 10^{-6} \mathrm{~K}^{-1}$ (Miyazaki等, 2009). 随着温度不断 变化, 骨骼化石内方解石与羟磷灰石膨胀收缩的体积 不同, 造成应力的局部集中, 产生微裂隙, 从而对化石 结构造成破坏. 二是由于外部围岩、骨骼化石和内部 填充物三者之间的热膨胀系数不同. 化石围岩是砂岩, 其热膨胀系数为 $5 \times 10^{-6} \sim 19 \times 10^{-6} \mathrm{~K}^{-1}$ (张秀华等, 2014); 骨骼化石基本是羟基磷灰石，其热膨胀系数为 $13.9 \times 10^{-6} \mathrm{~K}^{-1}$ (Miyazaki等, 2009); 填充物主要成分为 方解石, 其 $\alpha_{\text {max }}=26.5 \times 10^{-6} \mathrm{~K}^{-1} 、 \alpha_{\min }=5.6 \times 10^{-6} \mathrm{~K}^{-1}$ (吴福 全等, 2016). 在温度变化下, 以方解石为主的内部填充 物、骨骼化石和外部砂岩的热膨胀系数不同导致化石 产生热应力. 在昼夜温度的循环变化下, 围岩-骨骼化 石界面和骨骼化石-填充物界面会不断产生应力. 化石 因有机质流失, 其弹性韧性抗拉强度都急剧下降, 在长 期的应力作用下会使得化石开裂剥落.

化石开裂剥落的第二个原因是盐风化. 经过几十 年的研究, 学者们就可溶盐对多孔材料的破坏机理有 了比较全面的认识(靳治良等, 2017). 首先, 可溶盐在 结晶时产生的结晶压可对多孔材料造成破坏. $\mathrm{NaCl}$ 溶 解重结晶时产生的结晶压力可达221.9MPa (Winkler, 1975), $\mathrm{Na}_{2} \mathrm{SO}_{4}$ 结晶产生的结晶压超过 $7 \mathrm{MPa}$ (靳治良 等, 2015). 其次, 盐分水化作用产生的水化压可对多 孔材料的孔隙壁造成压力. 例如, $\mathrm{Na}_{2} \mathrm{SO}_{4}$ 吸收水分变 成 $\mathrm{Na}_{2} \mathrm{SO}_{4} \cdot 10 \mathrm{H}_{2} \mathrm{O}$ 的过程中体积膨胀, 在孔隙中产生的 压力可高达 $48 \mathrm{MPa}$ (Goudie, 1998). 最后, 盐分结晶带 来的热量变化以及盐晶体的热膨胀系数与多孔材料 有差异，也可对多孔材料产生温差应力(Goudie, 1998). 可见，可溶盐对多孔材料的破坏是巨大的. 由 表4可知, 骨骼化石含有大量 $\mathrm{Na}^{+} 、 \mathrm{Ca}^{2+} 、 \mathrm{Cl}^{-} 、 \mathrm{SO}_{4}{ }^{2-}$ 和 $\mathrm{NO}_{3}{ }^{-}$, 骨骼化石应含有较多的 $\mathrm{NaCl} 、 \mathrm{Na}_{2} \mathrm{SO}_{4}$ 、 $\mathrm{CaCl}_{2}$ 等可溶盐. 化石从常年干旱的哈密地区运输至 相对湿润且四季变化明显的北京后, 随着外界环境温
湿度的变化, $\mathrm{NaCl} 、 \mathrm{Na}_{2} \mathrm{SO}_{4}$ 等可溶盐的溶解重结晶作 用反复进行，必然产生巨大的结晶压和水化压. 实验 表明, 新鲜骨骼的抗拉强度为47 66MPa, 随着有机质 成分流失，其弹性韧性抗拉强度都急剧下降. 保存条 件良好的考古出土骨骼，其抗拉强度下降至 $38 \mathrm{MPa}$; 保存差的骨骼, 其抗拉强度仅有4MPa左右(TurnerWalker和Parry, 1995). 翼龙化石在埋藏后的成岩过程 中, 有机质流失, 其抗拉强度急剧下降. 当温湿度发生 变化, 可溶盐不断溶解重结晶, 此过程中释放的结晶 压和水合压已经超过化石的抗拉强度，使化石开裂 剥落.

研究表明, 当文物中的 $\mathrm{NO}_{3}{ }^{-}$含量小于 $500 \mu \mathrm{g} \mathrm{g}^{-1}$ 时, 不存在风险; 大于 $1500 \mu \mathrm{g} \mathrm{g}^{-1}$ 时, 则需要进行脱盐处 理. 对于 $\mathrm{Cl}^{-}$, 小于 $300 \mu \mathrm{g} \mathrm{g}^{-1}$, 对文物没有风险; 大于 $1000 \mu \mathrm{g} \mathrm{g}^{-1}$ 时, 建议进行脱盐处理(Ottosen等, 2007). 骨 骼化石的 $\mathrm{Cl}^{-}$和 $\mathrm{NO}_{3}{ }^{-}$均超过安全标准, 应进行相关保 护措施来减缓可溶盐对化石带来的伤害. 鉴于哈密化 石及围岩标本大小不一, 形态各异, 尤其对水非常敏 感，大量水分的引入会使化石的机械强度急剧下降， 不适宜使用传统贴敷的脱盐方法(李颖等, 2019). 引入 结晶抑制剂可降低晶体生长速率，从而减缓可溶盐对 多孔材料造成的伤害, 应是较为理想的盐害治理措施 (Granneman等, 2019).

综上所述, 可将化石风化机理概括如图8所示. 一 方面, 新疆戈壁滩昼夜温差较大, 因化石各组分的热膨 胀系数不同, 在化石内部产生巨大热应力. 对山东诸城 等地恐龙化石的风化研究发现, 在露天阳光直射保存 环境下的恐龙化石风化严重, 而在室内保存且使用环 氧树脂加固封护处理的化石风化程度较轻(刘风臣等, 2019). 这是因为在阳光照射下, 化石受热不均匀, 其内 部热应力分布不均导致化石发生热破裂(杜圣贤等, 2015; 张尚坤等, 2018). 可见, 热应力是引起化石破裂 风化的重要因素. 另一方面, 化石当中可溶盐含量较 高, 在温湿度变化下, 可溶盐产生的结晶压和水合压 等压力超过化石自身的内部结合力限度时, 就会在化 石内部产生微裂缝. 陶质文物的酥粉(赵静等, 2015)、 砖石文物的风化(赵光涛等, 2015; 纪娟等, 2020)乃至 现代混凝土建筑的腐蚀(滕小梅, 2001; 王军等, 2013) 都与可溶盐产生的结晶压和水合压有关.

为避免因温度变化而在化石内部产生热应力进而 导致其开裂, 应将化石保存在恒温环境下, 同时可对化 


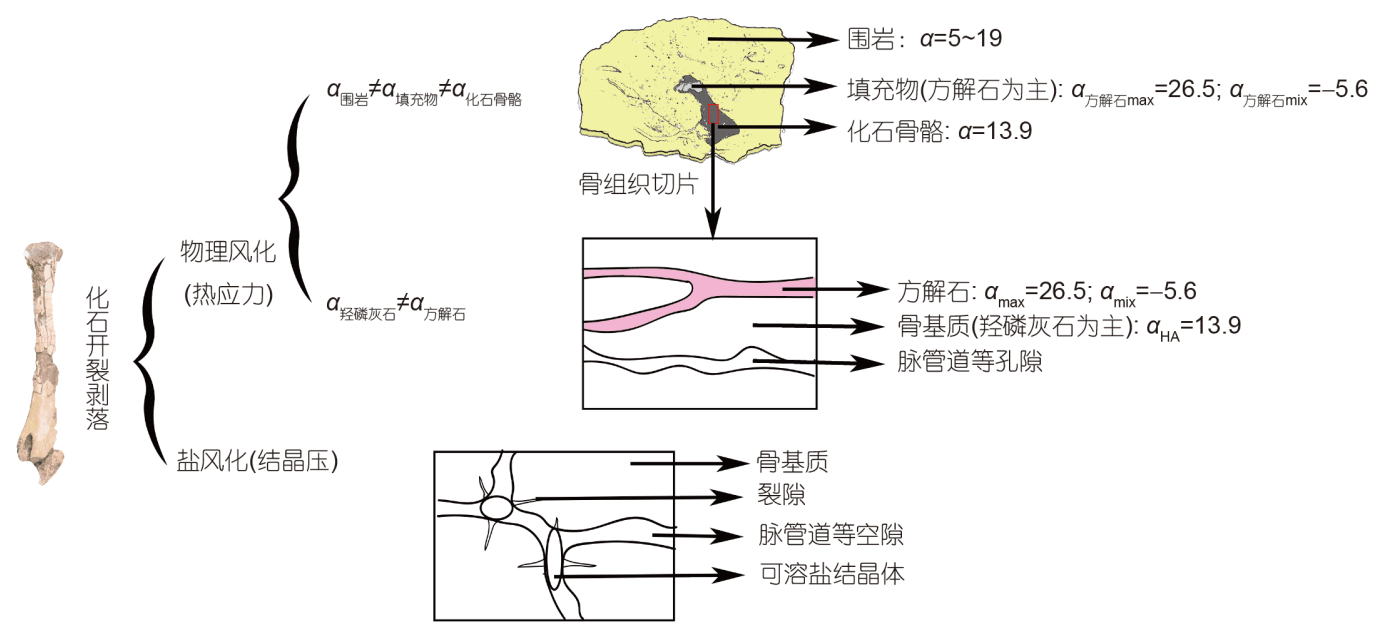

图 8 (网络版彩图)化石风化机理示意图

$\alpha$ 为热膨胀系数, 单位 $10^{-6} \mathrm{~K}^{-1} ; \mathrm{HA}$ 为羟磷灰石简写; 骨骼中空填充物部分的物相组成较为复杂, 鉴于方解石占比最高 $(45 \%$ 以 $)$ 且方解石的热

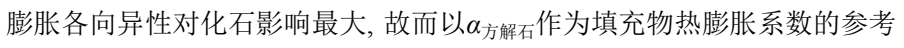

石进行加固处理, 提高化石强度. 结合哈密翼龙化石及 围岩的特殊性(水敏感性, 遇水酥粉), 在文物保护行业 广泛使用的贴敷脱盐法并不适宜治理其盐害(李颖等, 2019)；向化石添加影响盐溶液结晶的试剂(亚铁氧化 钾等结晶抑制剂)或是较为可行的方法. 新疆地区盐渍 化土壤分布广泛、类型复杂(张翠英和匡晓帆，1990), 在此地区发掘出土的其他古生物化石材料也很可能受 到盐风化的影响，建议发掘工作者在条件允许情况下 尽量将化石保存在温湿度较为恒定的环境中，避免可 溶盐溶解-重结晶循环变化对化石造成的损害. 另外, 也可采集少量化石及围岩样品进行离子色谱测试，明 确化石是否受到盐风化的影响. 这是首次尝试对新疆 出土的脊椎动物化石进行风化机理研究, 其结果对产 于极干旱高盐碱地区的化石保护具有普遍意义. 我国 甚至国际上很多化石产自相似的环境, 研究结果具有 潜在的应用价值.

\section{4 结论}

经过上述分析, 我们获得以下认识.

(1) 哈密翼龙骨骼化石主要成分是羟基磷灰石, 化 石在成岩交代作用下, $\mathrm{CO}_{3}{ }^{2-}$ 替代了部分骨羟磷灰石中 的 $\mathrm{PO}_{4}{ }^{3-}$, 在脉管道内填充少量方解石和锰质胶结物. 中空骨骼内的填充物主要为方解石，夹杂石英、长石 等其他碎屑颗粒，与围岩成分基本一致。骨骼化石中
含有大量的 $\mathrm{Cl}^{-} 、 \mathrm{NO}_{3}^{-} 、 \mathrm{SO}_{4}{ }^{2-} 、 \mathrm{Na}^{+}$和 $\mathrm{Ca}^{2+}$ 等离子, 可 溶盐总含量较高.

(2) 温差变化是哈密翼龙化石开裂剥落主要原因 之一，随着戈壁滩剧烈的温度变化，化石不同材质之 间由于热膨胀系数的差异, 尤其是方解石的热膨胀各 向异性, 导致化石应力局部集中产生破裂进而剥落.

(3) 翼龙骨骼当中含有大量可溶盐, 在温湿度变化 下，可溶盐溶解重结晶产生的巨大压力超过了骨骼化 石的抗拉强度从而使化石开裂剥落.

(4) 可采用施加结晶抑制剂从而避免可溶盐反复 溶解-结晶带来的风化破坏，同时可使用有机硅等对化 石进行加固处理以提高其强度，这对产于极干旱高盐 碱地区化石的保护具有普遍意义.

致谢感谢中国科学院古脊椎动物与古人类研究所周红 娇、向龙、金迅、李阳、陈鹤、张全俊、王俊霞、刘晓 迪、宋石玮及朱旭峰在野外样品采集及实验分析中提供 的大力帮助; 感谢中国文化遗产研究院陈岳、杜靖、胡 凤丹在离子色谱分析和北京大学崔剑锋教授、周雪琪及 姜晓晨阳在X射线荧光实验中的指导与帮助. 感谢审稿专 家及编委对本文提出的建议.

\section{参考文献}

邓建国, 刘东亮, 叶勇. 2010a. 恐龙骨骼化石保护材料研究. 河南师 范大学学报(自然科学版), 38: 156-159 
邓建国, 彭光照, 金永中, 叶勇. 2010b. 自贡地区恐龙骨骼化石及围 岩特征的研究. 光谱实验室, 27: 192-196

杜圣贤, 张尚坤, 于学峰, 陈军, 宋香锁, 贾超, 张国荣. 2015. 恐龙化 石风化效应的 TM耦合分析研究. 山东国土资源, 31: 65-70

杜远生, 童金南. 2009. 古生物地史学概论. 武汉: 中国地质大学出版 社. 6

纪娟, 王永进, 马涛, 王展, 董少华, 周伟强. 2020. 茂陵石刻表面污染 物和可溶盐的分析研究. 文物保护与考古科学, 32: 22-28

靳治良, 陈港泉, 夏寅, 苏伯民, 周铁, 吕功煊. 2015. 硫酸盐与氯化物 对壁画的破坏性对比研究—硫酸钠超强的穿透、迁移及结晶 破坏力证据. 文物保护与考古科学, 27: 29-38

靳治良, 刘端端, 张永科, 陈港泉, 夏寅, 苏伯民, 周铁, 吕功煊, 罗宏 杰. 2017. 盐分在文物本体中的迁移及毁损机理. 文物保护与考 古科学, 29: 102-116

赖琛. 2006. 反胶团一热液法合成羟基磷灰石纳米线及其机理研究. 博士学位论文. 长沙: 湖南大学. 31

李颖, 罗武干, 杨益民, 汪䈗林. 2019. 天山哈密翼龙化石围岩风化机 理初步分析. 古生物学报, 58: 515-525

梁涛. 2009. 新疆地区土遗址病害类型及成因初步分析. 考古与文物: 103-106

刘凤臣, 张尚坤, 田京祥, 贾超, 陈军, 陈文芳. 2019. 阳光直射、室内 遮阴和涂保护层对恐龙化石风化影响的模拟研究. 山东国土资 源, 35: 58-61

刘林西. 2014. 澄城县出土象牙化石病害机理与加固保护研究. 考古 与文物: $100-103$

沈卫, 顾燕芳, 刘昌胜, 孙祥明, 胡黎明. 1996. 羟基磷灰石的表面特 性. 硅酸盐通报: 45-52

滕小梅. 2001. 日本海沿岸混凝土桥的盐害对策. 国外桥梁: 57-63

汪䈗林, 蒋顺兴, 程心. 2018. 哈密翼龙及其3D胚胎化石研究. 科技导 报, 36: 11-19

王军, 陈静静, 鞠泽青. 2013. 盐害环境钢筋混凝土井壁腐蚀机理与 类型研究. 科学技术与工程, 13: 1690-1694

翁诗甫, 徐怡庄. 2016. 傅里叶变换红外光谱分析(第三版). 北京: 化 学工业出版社

吴福全, 吴闻迪, 苏富芳, 史萌. 2016. 光学方解石晶体温度特性. 光 学学报, 36: 267-272

张翠英, 匡晓帆. 1990. 用离子色谱仪测定新疆土壤中可溶盐与水质 矿化度. 干旱区研究: 63-72

张尚坤, 于学峰, 贾超, 杜圣贤, 宋香锁, 陈诚, 刘风臣, 陈军, 陈文芳. 2018. 热应力对恐龙化石风化损坏的影响研究. 山东国土资源, 34: $42-48$

张尚坤, 于学峰, 贾超, 杜圣贤, 宋香锁, 刘凤臣, 陈军, 陈文芳. 2019. 影响恐龙化石及围岩风化破坏的主要因素及风化机理研究. 山 东国土资源, 35: 25-31

张文斌. 2016. 塔克拉玛干沙漠土壤热通量变化特征分析. 硕士学位 论文. 新疆: 新疆师范大学. 30
张秀华, 杨桦, 许雅莹. 2014. 材料手册6. 哈尔滨: 哈尔滨工业大学出 版社

赵光涛, 李玉虎, 张译丹, 杜德新. 2015. 西安明城墙砖石表面风化因 素分析. 陕西师范大学学报(自然科学版), 43: 54-58

赵静, 王丽琴, 罗宏杰, 李伟东, 容波, 周铁. 2015. 可溶盐 $\mathrm{NaCl}$ 和 $\mathrm{CaCl}_{2}$ 对陶质文物的酥粉作用. 文物保护与考古科学, 27: 1-6

Berna F, Matthews A, Weiner S. 2004. Solubilities of bone mineral from archaeological sites: The recrystallization window. J Archaeol Sci, 31: 867-882

Deeming D C. 2017. How pterosaurs bred. Science, 358: 1124-1125

Fleet M E, Liu X. 2003. Carbonate apatite type A synthesized at high pressure: New space group and orientation of channel carbonate ion. J Solid State Chem, 174: 412-417

Goudie A. 1998. The salt weathering hazard in deserts. In: Kalvoda J, Rosenfeld C L, eds. Geomorphological Hazards in High Mountain Areas. Dordrecht: Springer. 107-120

Granneman S J C, Lubelli B, van Hees R P J. 2019. Mitigating salt damage in building materials by the use of crystallization modifiers -A review and outlook. J Cultural Heritage, 40: 183-194

Hackett C J. 1981. Microscopical focal destruction (tunnels) in exhumed human bones. Med Sci Law, 21: 243-265

Howie F M P. 1984. Materials used for conserving fossil specimens since 1930: A review. Stud Conserv, 29: 92-97

López-Polín L. 2012. Possible interferences of some conservation treatments with subsequent studies on fossil bones: A conservator's overview. Quat Int, 275: 120-127

López-Polín L, Ollé A, Cáceres I, Carbonell E, Bermúdez de Castro J M. 2008. Pleistocene human remains and conservation treatments: The case of a mandible from Atapuerca (Spain). J Human Evol, 54: 539-545

Mallouchou M S, Stathopoulou E T, Theodorou G E. 2019. How do fossilized mammalian bones behave during chemical conservation? The histological case studies of Tilos and Kerassia. Geoheritage, 11: 597-614

Martill D M. 2014. Palaeontology: Which came first, the pterosaur or the egg? Curr Biol, 24: R615-R617

Miyazaki H, Ushiroda I, Itomura D, Hirashita T, Adachi N, Ota T. 2009. Thermal expansion of hydroxyapatite between $-100{ }^{\circ} \mathrm{C}$ and $50{ }^{\circ} \mathrm{C}$. Mater Sci Eng-C, 29: 1463-1466

Monge G, Carretero M I, Pozo M, Barroso C. 2014. Mineralogical changes in fossil bone from Cueva del Angel, Spain: Archaeological implications and occurrence of whitlockite. J Archaeol Sci, 46: 6-15

Newesely H. 1989. Fossil bone apatite. Appl Geochem, 4: 233-245

Ottosen L M, Pedersen A J, Rörig-Dalgaard I. 2007. Salt-related problems in brick masonry and electrokinetic removal of salts. $\mathrm{J}$ 
Build Apprais, 3: 181-194

Peng X, Wang Y, Ma X F, Bao H, Huang X, Zhou H, Luo H, Wang X. 2020. Sol-gel derived hybrid materials for conservation of fossils. J Sol-Gel Sci Technol, 94: 347-355

Pfretzschner H U, Tütken T. 2011. Rolling bones-Taphonomy of Jurassic dinosaur bones inferred from diagenetic microcracks and mineral infillings. Palaeogeogr Palaeoclim Palaeoecol, 310: 117123

Ressler T, Wienold J, Jentoft R E. 2001. Formation of bronzes during temperature-programmed reduction of $\mathrm{MoO}_{3}$ with hydrogen - $\mathrm{An}$ in situ XRD and XAFS study. Solid State Ion, 141-142: 243-251

Ronald E M. 1999. Taphonomy: A Process Approach. Cambridge: Cambridge University Press

Shemesh A. 1990. Crystallinity and diagenesis of sedimentary apatites. Geochim Cosmochim Acta, 54: 2433-2438

Turner-Walker G. 1998. The West Runton fossil elephant: A preconservation evaluation of its condition, chemistry and burial environment. Conservator, 22: 26-35

Turner-Walker G. 2012. Early bioerosion in skeletal tissues: Persistence through deep time. Neues Jahrb Geol Palaontol Abh, 265: $165-183$
Turner-Walker G, Parry T V. 1995. The tensile strength of archaeological bone. J Archaeol Sci, 22: 185-191

Wang L, Fan H, Liu J, Dan H, Ye Q, Deng M. 2007. Infrared spectroscopic study of modern and ancient ivory from sites at Jinsha and Sanxingdui, China. Mineral Mag, 71: 509-518

Wang X, Kellner A W A, Jiang S, Cheng X, Wang Q, Ma Y, Paidoula Y, Rodrigues T, Chen H, Sayão J M, Li N, Zhang J, Bantim R A M, Meng X, Zhang X, Qiu R, Zhou Z. 2017. Egg accumulation with 3D embryos provides insight into the life history of a pterosaur. Science, 358: 1197-1201

Wang X, Kellner A W A, Jiang S, Wang Q, Ma Y, Paidoula Y, Cheng X, Rodrigues T, Meng X, Zhang J, Li N, Zhou Z. 2014. Sexually dimorphic tridimensionally preserved pterosaurs and their eggs from China. Curr Biol, 24: 1323-1330

Weiner S. 2010. Microarchaeology: Beyond the Visible Archaeological Record. New York: Cambridge University Press. 59

Weiner S, Bar-Yosef O. 1990. States of preservation of bones from prehistoric sites in the Near East: A survey. J Archaeol Sci, 17: 187196

Winkler E M. 1975. Stone: Properties, Durability in Man's Environment. 2nd ed. New York: Spinger-Verlag Wien GmnH. 121

(责任编委: 朱敏) 